\title{
A Rare Cause of Seizure: Gitelman Syndrome
}

\author{
Türkyılmaz HN, Berksoy EA, Gürbüz G, Deveci R, Serdaroğlu E and Ünalp A* \\ Dr. Behçet Uz Childrens Disease and Pediatric Surgery Training and Research Hospital-İzmir-Turkey
}

*Corresponding author: Ünalp A, Professor of Pediatric Neurology, Atatürk Caddesi, No 354, Kat 6 Daire 12, Kent Apartman1, 35320 Alsancak, İzmir-Türkiye, Fax: 00902324892315, Tel: 0090505 2211693, E-mail: aycanunalp67@ gmail.com

Citation: Türkyılmaz HN, Berksoy EA, Gürbüz G, Deveci R, Serdaroğlu E, et al. (2017) A Rare Cause of Seizure: Gitelman Syndrome. J Neurosci Neuropsyc 1: 105. doi: 10.18875/2577-7890.1.105

Article history: Received: 08 November 2017, Accepted: 27 December 2017, Published: 28 December 2017

\begin{abstract}
Gitelman syndrome is autosomal recessive disease which is a broad clinical spectrum with hypokalemia, metabolic alkalosis, hypomagnesemia and hypocalciuria caused by reabsorption of $\mathrm{Na}$ and $\mathrm{Cl}$ in distal tubule. Prevalence of this disease is thought to be 1.2 cases per million. Previously, tetanic convulsion as well as resistant epileptic convulsions has been reported representing to Gitelman Syndrome. The management of the disease varies according to the patients symptoms. An 8 years old girl with contraction on feet and hands which have started since 3 years old and intermittently repeated. The patient were referred to emergency service and diagnosed with the Gitelman syndrome. When the case was admitted to our clinic, she has tetanic convulsion. Her physical examinations with EEG and brain MRI findings were within normal limits. Laboratory findings included hypokalemia, normocalcemia, metabolic alkalosis, hypomagnesemia and hypocalciuria. In genetic study which made thought to be Gitelman syndrome substantially was found homozygous mutation at SLC12A3 gene. Laboratory findings improved by treatment with potassium and magnesium and tetanic convulsion have not been repeated.

In conclusion, we presented a patient with Gitelman syndrome who had a rarely seen disease causing tetanic convulsions.
\end{abstract}

Keywords: Gitelman Syndrome; Tetany; Renal Tubular Disorder; Convulsion

\section{Introduction}

Gitelman syndrome which is described by Gitelman, Graham and Welt is autosomal resesive disease which is a broad clinical spectrum with hypokalemia, metabolic alkalosis, hypomagnesemia and hypocalciuria caused by reabsorbtion of $\mathrm{Na}$ and $\mathrm{Cl}$ in distal tubule. Cases who hadn't prematurity, polihidramniosis in past, usually become symptomatic in early childhood or adolescence. Typical presentation include in salt apetite, spasm of muscle, paralyze, tingling, perioral drowsiness, nokturia and hypotension [1]. Diagnosis made by clinical features, laboratory findings, renal function tests and now confirmed by genetic studies [2]. Prevalence of Gitelman syndrome is thought to be 1.2 cases per million. Although what percentage of Gitelman syndrome patient present with seizures is not known convulsions are not common. It has been reported that convulsions due to severe metabolic alkalosis or hypomagnesemia can occur [3].

Treatment is usually aimed at correcting electrolyte imbalance. This case was presented to emphasize that Gitelman syndrome that is a rare disease and that has the various clinical appearances, should be considered in the differential diagnosis of seizures.

\section{Case Report}

An 8 years old girl with contraction on feet and hands was admitted to emergency service with diagnose convulsion. Complaints have started since 3 years old and intermittently repeated especially during writing. The girl borned as $3400 \mathrm{gr}$ by $\mathrm{C} / \mathrm{S}$ following the normal course of term pregnancy and as second child of parents who are second degree relative. There is no history of infection, chronic disease or drug intake. Physical examination is unremarkable except contraction on bilateral feet and hands during 5 minutes. In the initial evaluation of patients, arterial blood pressure was in the normal range $(95 / 60 \mathrm{mmHg})$ and hemogram parameters are normal, infection criteria were negative. Renal function tests were within normal limits (serum BUN 7.7mg / $\mathrm{dL}$, creatinine $0.4 \mathrm{mg} / \mathrm{dL})$. Serum potassium $2 \mathrm{mmol} / \mathrm{l}(3.5-5.5 \mathrm{mmol} / \mathrm{l})$, serum calcium was $8.9 \mathrm{mg} / \mathrm{dl}(8.5-11 \mathrm{mg} / \mathrm{dl})$, serum chloride $95 \mathrm{mmol} / \mathrm{l}$ (95 to $110 \mathrm{mmol} / \mathrm{l}$ ) due to intravenous potassium replacement therapy. However, it was observed 
that attacks of tetany repeated. Blood gase analyze revealed metabolic alkalosis (pH 7:53, HCO3 $32.5 \mathrm{mmol} / 1$, PCO2 $69 \mathrm{~mm}$ $\mathrm{Hg})$. Plasma magnesium level of patient was $1.1 \mathrm{mg} / \mathrm{l}(1.6-2.6 \mathrm{mg} / \mathrm{l})$ and spot urine excretion of chlorine was excess $(77 \mathrm{mmol} / \mathrm{l})$, calcium was decrease $(<2 \mathrm{mg} / \mathrm{dl})$, magnesium, sodium and potassium was normal range. Brain MRI and EEG which are taken for etiology of seizure detected no pathology. The clinical findings were healed after orally magnesium replacement together with orally potassium to diagnose with renal tubular dysfunction because of hypokalemia, metabolic alkalosis, and hypomagnesemia.

In patients' clinical findings and laboratory investigations, it was detected hypokalemia, hypomagnesemia, high plasma bicarbonate concentration, hypocalsiuria which are characteristic findings of Gitelman syndrome. In genetic study which made thought to be Gitelman syndrome substantially was found homosigot mutation at SLC12A3 gene and diagnose was confirmed. Informed consent from patient was collected. The case of follow-up having continued.

\section{Discussion}

GS is autosomal recessive renal tubular disorder caused by inactivation of thiazide- sensitive sodium-chloride co-transporter encoding SLC12A3G gene. It is characterized by hypokalemic metabolic alkalosis, hypomagnesemia and hypocalciuria. Each of gender is affected equally and usually occurs in early childhood and adolescence as in our case. Most patients are asymptomatic or mild intermittent cramping, fatigue and muscle weakness [4]. However, our patient was admitted with severe tetanic convulsions. GS which has a very wide clinical spectrum, as indicated by Cruz, et al. can appear at $6 \%$ with periodic paralysis [5]. While seizures are not common in GS, convulsions due to severe metabolic alkalosis or hypomagnesemia can occur and in such cases, the serum $\mathrm{Mg}$ levels are extremely reduced $(<1 . \mathrm{Mg} / \mathrm{dl})[3,6]$.

In the past, GS mimic with Bartter syndrome, but they seperate because GS have hypocalciuria. In Bartter syndrome, severe hypomagnesemia is rare but $20 \%$ of patients have mild hypomagnesemia. This clinic may be shown in chronic use of diuretics, laxatives, vomiting and Bartter syndrome [2]. Cause of secondary causes must be excluded before GS is diagnosed. Das, et al. described basal ganglion calcification by brain MRI in 1 patient who appeal with tetany, seizure and periodical paralyses and was diagnosed GS. Our patients have no pathology in brain MRI. Relationship between calcification and GS is still not obvious [2].

Treatment usually aims to correct electrolyte imbalance include magnesium, potassium replacement and spironolacton [1]. Although all type of magnesium can be use, $\mathrm{MgCl}^{2}$ prefer because it compensate for the loss of urinary Cl-. Our patient's laboratory findings improved by treatment with potassium and magnesium treatment. The patient's EEG and brain MRI findings were normal. The patient history doesn't indicate seizure in the past. The follow-up of our patient is still ongoing. She had complaints of numbness and contraction in her hands and her ions were found to be low. Since the patient's compliance with the drug treatment was not good, it was suggested that the diet be rich in potassium and magnesium.

Besides GS, there are cases of inherited hypokalemia salt-wasting renal tubular disorders, like SeSAME or EAST syndrome, in which convulsion is one of the chief complaints. SeSAME (Seizures, Sensorineural Deafness, Ataxia, Mental Retardation, and Electrolyte Imbalance) or EAST (Epilepsy, Ataxia, Sensorineural Deafness, and Tubulopathy) syndrome is caused by mutations of the K (+) channel KCNJ10 (Kir4.1) gene, which is an autosomal recessive disease [7,8]. These diseases were excluded by the absence of other accompanying findings of our patient and genetic testing.

In the study made by Liaw, et al. indomatesine together with orally magnesium and potassium treatment was taken 3 patients with GS. They show that $4 \mathrm{mg} / \mathrm{kg}$ / day dose of indomethacin provide better growth [9]. Our patient did not have growth retardation in follow-up and responded to oral potassium and magnesium. Generally prognoses of GS is perfect. Makino, et al. reported the case of a school boy who initially presented with a generalized convulsion that the patient has persistent hypokalemia and metabolic alkalosis. They confirmed that the patient actually had GS, based on the two mutations of the SLC12A3 gen and they claimed that a patient showing persistent hypokalemia and metabolic alkalosis should be tested for GS and, if possible, diagnosed at the genetic level, even if the patient exhibits atypical clinical symptoms [10].

Consequently, GS is a rare disease and have broad clinical spectrum and may occur with seizure, tetany, periodical paralyze. Therefore GS should be considered in differential diagnose of patient with seizure, spasm or periodic paralyze which have electrolyte imbalance and blood acid base disorder.

\section{References}

1. Rodriguez-Soriano J (1998) Bartter and related syndromes: the puzzle is almost solved. Pediatr Nephrol 12: 315-27.

2. Das SK, Ghosh A, Banerjee N, Khaskil S (2012) Gitelman's syndrome presenting with hypocalcaemia, basal ganglia calcification and periodic paralysis. Singapore Med J 53: e222-4.

3. Skalova S, Neuman D, Lnenicka P, Stekrova J (2013) Gitelman syndrome as a cause of psychomotor retardation in a toddler. Arab J Nephrol Transplant 6: 37-9.

4. Gitelman HJ, Graham JB, Welt LG (1966) A new familial disorder characterized by hypokalemia and hypomagnesemia. Trans Assoc Am Physicians 79: 221-35.

5. Cruz DN, Shaer AJ, Bia MJ, Lifton RP, Simon DB (2001) Gitelman's syndrome revisited: an evaluation of symptoms and health-related quality of life. Kidney Int 59: 710-7.

6. Weisleder P, Tobin JA, Kerrigan JF, Bodensteiner JB (2002) Hypomagnesemic seizures: case report and presumed pathophysiology. J Child Neurol. 59-61.

7. Freudenthal B, Kulaveerasingam D, Lingappa L, Shah MA, Brueton L, et al. (2011) KCNJ10 mutations disrupt function in patients with EAST syndrome. Nephron Physiol 119: p40-8. 
8. Scholl UI, Dave HB, Lu M, Farhi A, Nelson-Williams C, et al. (2012) SeSAME/EAST syndrome-phenotypic variability and delayed activity of the distal convoluted tubule. Pediatr Nephrol 27: 2081-90.

9. Liaw LC, Banerjee K, Coulthard MG (1999) Dose related growth response to indometacin in Gitelman syndrome. 81: 508-10.

10. Makino S, Tajima T, Shinozuka J, Ikumi A, Awaguni H, et al. (2014) Gitelman syndrome in a school boy who presented with generalized convulsion and had a R642H/R642W mutation in the SLC12A3 gene. Case Rep Pediatr 279-389. 